Canadian Journal of Fisheries and Aquatic Sciences, Vol. 60, No. 11, 2003, pp. 1314-1323.

(C) National Research Council Canada. All rights reserved.

http://pubs.nrc-cnrc.gc.ca/eng/index.html

ISSN: 0706-652X

doi:10.1139/f03-112

\title{
Zooplankton biomass enhances growth, but not survival, of first-feeding Pomoxis spp. Larvae
}

\author{
David B. Bunnell, María J. González, and Roy A. Stein \\ D.B. Bunnell and R.A. Stein. Aquatic Ecology Laboratory, Department of Evolution, Ecology, \\ and Organismal Biology, The Ohio State University, M.J. González. Department of Zoology, \\ Miami University, Oxford, $\mathrm{OH}$
}

\begin{abstract}
We used otoliths to estimate growth and survival of white (Pomoxis annularis) and black (Pomoxis nigromaculatus) crappie larvae in five Ohio reservoirs. Because Pomoxis spp. larvae are among the smallest freshwater larvae and competition with gizzard shad larvae (Dorosoma cepedianum) is likely, we hypothesized that first-feeding Pomoxis spp. larvae would be susceptible to slow growth and starvation. We estimated survival by comparing proportional weekly cohort distributions of Pomoxis spp. larvae and juveniles. When distributions differed, a cohort survival index was evaluated against density of appropriately sized zooplankton biomass (crustaceans and rotifers), as well as temperature, turbidity, and density of all limnetic larvae that occurred during hatch week, when exogenous feeding began. Growth of first-feeding larvae $(<10$ days old $)$ increased with total zooplankton biomass $\left(r^{2}=0.64\right)$; growth of larvae aged 10-16 days was unrelated to all measured variables. Survival was positively correlated with zooplankton biomass in only one of four reservoirs, and other variables did not correlate as expected. This result casts doubt on whether zooplankton contributes to survival of freshwater larvae.
\end{abstract}

\section{Introduction}

Variable survival of young fish can drive population fluctuations (Houde 1987). To explain variable offspring survival of fishes, early marine studies focused on the role of starvation during the period when larvae shift from feeding endogenously on yolk sacs to exogenously on zooplankton (Hjort 1914). This hypothesis later was extended to freshwater environments. In experiments, survival of freshwater larvae generally increases with zooplankton density (e.g., Hart and Werner 1987; Welker et al. 1994). Despite experimental support for this hypothesis, zooplankton prey densities are generally unrelated to survival in freshwater field studies (e.g., Welker et al. 1994; Betsill and Van Den Avyle 1997; Garvey et al. 2002). The positive relationship between fish size and resistance to starvation (Hunter 1981; Miller et al. 1988) may help explain these conflicting results. Larvae hatching at larger sizes have the advantage of potentially higher energy reserves, as well as larger gapes, which permit access to more (i.e., larger) zooplankton, than those hatching at smaller sizes (Hunter 1981). Because freshwater larvae are generally larger at hatch than marine larvae, Houde (1994) predicted that larval starvation would be less likely to occur in freshwater larvae. Thus, starvation during the larval stage may be rare for freshwater fishes.

Beyond the direct effects of starvation, low zooplankton densities also can influence larval survival via indirect effects. First, starved larvae swim more slowly than better-fed conspecifics, which may increase their vulnerability to predators (Rice et al. 1987). Second, low zooplankton densities and resultant slow growth increase the length of vulnerability to gapelimited predators (Crowder et al. 1987). Finally, small size resulting from slow growth will continue to limit the sizes of available zooplankton prey. Thus, faster growth and resultant larger 
size likely confers a suite of survival advantages to age-0 fishes (Miller et al. 1988).

Growth and survival of larvae can be influenced by factors other than density of prey. Temperature can modify egg development (Siefert 1968) and influence larval growth (Houde 1997). Turbidity can alter the visual environment for larvae, which in turn can mediate growth rates (Miner and Stein 1993). Density of co-occurring larval competitors also may reduce growth and survival of larvae by reducing densities of zooplankton prey (DeVries and Stein 1992). Herein, we sought to evaluate an extension of Hjort's (1914) critical period hypothesis with white (Pomoxis annularis) and black (Pomoxis nigromaculatus) crappie, popular freshwater sport fishes that frequently exhibit variable recruitment. Specifically, we evaluated how density of appropriately sized zooplankton biomass, water temperature, turbidity, and density of fish larvae occurring during the week that larvae hatch and become exogenous feeders influences their growth and survival to the juvenile stage.

We hypothesized that first-feeding Pomoxis spp. larvae may be vulnerable to low zooplankton densities because of their small size and potential vulnerability to competitors in Ohio reservoirs. In a compilation by Auer (1982) of 99 freshwater species (including 22 families) native to the Great Lakes basin, mean length at hatch was $6.24 \mathrm{~mm}$; white crappie was the smallest species and black crappie was the third smallest (Auer 1982). Owing to the positive relationship between larval size at hatch and resistance to starvation (Miller et al. 1988), Pomoxis spp. are likely more vulnerable to starvation than most freshwater larvae. Second, interspecific competition with gizzard shad (Dorosoma cepedianum) larvae may reduce available zooplankton densities for crappie larvae. Previous research in hypereutrophic Ohio reservoirs has documented bluegill (Lepomis macrochirus) survival to be compromised by competitive interactions with gizzard shad (reviewed by Stein et al. 1995). High densities of age-0 gizzard shad deplete crustacean zooplankton (DeVries and Stein 1992), which in turn reduces survival of bluegill larvae (DeVries and Stein 1992; Garvey et al. 1998). Timing of larval hatch is critical: larvae hatching after the peak density of larval gizzard shad survive poorly (DeVries and Stein 1992; Garvey and Stein 1998). In 24 reservoir and year combinations in Ohio, the peak of bluegill larval density occurs at the same time as $(36 \%)$ or after $(40 \%)$ the peak of gizzard shad (Garvey and Stein 1998). Similarly, peak density of Pomoxis spp. larvae occurs at the same time as (21\%) or after (41\%) the peak density of gizzard shad larvae across 21 Ohio reservoir and year combinations (D.B. Bunnell, unpublished data). Because diets of first-feeding Pomoxis spp. And gizzard shad larvae overlap (DeVries et al. 1998), crappie larvae also may be vulnerable to competitive interactions with gizzard shad.

We used otoliths to understand how zooplankton density, water temperature, turbidity, and density of fish larvae (i.e., mostly gizzard shad) influenced the growth and survival of Pomoxis spp. larvae. By providing fish age, otoliths provide estimates of both growth rate (e.g., Claramunt and Wahl 2000) and hatch date. To understand factors influencing survival, we first determined whether the proportional weekly cohort distributions of limnetic larvae and surviving juveniles were different. If so, we then related weekly cohort survival to the aforementioned abiotic and biotic factors that occurred during the week that each cohort hatched and began feeding exogenously. 


\section{Materials and methods Species life history}

As different species, white and black crappies often co-occur and can hybridize (Smith et al. 1994). Although white crappies predominate in our study reservoirs (Table 1), the two species were pooled in this study because the larvae cannot be visually distinguished. Adults of both species spawn for 6-8 weeks during late spring through early summer (Pope and Willis 1998; D.B. Bunnell, unpublished data), exhibiting similar reproductive strategies as males build nests in the littoral zone (0.2- to 0.8-m depth; Siefert 1968) and then provide nest defence to incubating eggs (2-4 days) and embryos (i.e., yolk-sac larvae, 2-6 days; Siefert 1968). Larvae depart the nest at about the time of yolk-sac absorption (Siefert 1968), migrating to the limnetic zone where exogenous feeding begins. As larvae grow to the juvenile stage, both species migrate to benthic (offshore) habitat, where zooplankton remain their primary prey (Pine and Allen 2001; D.B. Bunnell, unpublished data).

\section{Field and laboratory}

\section{Zooplankton sampling and estimation}

Zooplankton were sampled weekly during May-June from five reservoirs during 2000 (Table 1). All collections were made during the day. With a conical, 54- $\mu \mathrm{m}$-mesh net, we sampled crustacean zooplankton and rotifers from $1 \mathrm{~m}$ above the reservoir bottom to its surface at fixed inflow and outflow sites. Upon collection, zooplankton were preserved in $70 \%$ ethanol. In the laboratory, cladoceran zooplankters were identified to genus (e.g., Daphnia, Bosmina, Eubosmina, Ceriodaphnia, Chydorus, Diaphanosoma, and Moina spp.), and copepod zooplankters were classified as calanoid, cyclopoid, or nauplii. Rotifers were counted and identified to genus using a compound microscope. Crustacean zooplankton were counted following Stahl and Stein (1994). We measured crustacean total length (excluding spines on cladocerans, but including up to the base of the caudal rami on copepods) to the nearest $0.01 \mathrm{~mm}$ of the first 22 individual crustaceans encountered in each taxon, using a Sigma Scan digitizing system (SPSS Inc., Chicago, Ill.). We then used taxon-specific, length - dry weight equations (Dumont et al. 1975; Rosen 1981; Culver et al. 1985) to convert length to biomass. We measured up to 25 individuals from each rotifer genus to the nearest $0.1 \mathrm{~mm}$ using the ocular micrometer on a compound microscope. Rotifer biomass was calculated using geometric formulas that approximate the volume of individuals (Ruttner-Kolinsko 1977). Volume was converted to wet weight assuming a specific gravity of 1 . Dry weight was estimated as $0.1 \times$ wet weight (Doohan 1973). 
Table 1. Characteristics of Ohio study reservoirs.

\begin{tabular}{llllllll}
\hline Reservoir & County & Code & $\begin{array}{l}\text { Surface area } \\
\left(\mathrm{km}^{2}\right)\end{array}$ & $\begin{array}{l}\text { Chlorophyll } a \\
\left(\mu \mathrm{g} \cdot \mathrm{L}^{-1}\right)\end{array}$ & $\begin{array}{l}\text { Trophic } \\
\text { status }\end{array}$ & $\begin{array}{l}\text { White crappie } \\
\text { population }(\%)\end{array}$ & $\begin{array}{l}\text { Mean white and black crappie } \\
\text { adult CPE (fish per net-night) }\end{array}$ \\
\hline Acton & Butler & AT & 2.44 & 51.68 & $>\mathrm{E}$ & 100.0 & 3.13 \\
Burr Oak & Morgan & BO & 2.69 & 7.13 & $\mathrm{M}$ & 98.2 & 0.97 \\
Caesar Creek & Warren & CC & 11.45 & 12.09 & $>\mathrm{M}$ & 84.9 & 1.80 \\
LaDue & Geauga & LD & 6.07 & 15.07 & $>\mathrm{M}$ & 88.9 & 2.28 \\
Pleasant Hill & Richland & PH & 3.44 & 25.26 & $>\mathrm{M}$ & 97.4 & 5.48 \\
\hline
\end{tabular}

Note: Chlorophyll $a\left(\mu \mathrm{g} \cdot \mathrm{L}^{-1}\right)$ was the grand mean of inflow- and outflow-integrated water samples collected weekly during May-June 2000. Trophic status was based on Wetzel (2001), where E represents eutrophic and M represents mesotrophic; greater or less than signs were used when concentrations fell between two trophic indicators. White crappie population was the percentage of adult white crappie (by number) of the total adult Pomoxis spp. populations (black crappie + white crappie) pooled over 4 years (1998-2001) of autumn trap-netting. Mean white and black crappie adult (age $\geq 2$ ) catch per effort (CPE, fish per net-night) provided a relative size of the adult populations during 1998-2001.

\section{Collection and aging of larvae}

Limnetic larvae were sampled weekly during the day in the top metre of water with neuston nets $(1 \mathrm{~m} \times 2 \mathrm{~m}$ wide mouth, 0.5 - $\mathrm{mm}$ mesh) from the same reservoirs, years, and sites in which zooplankton were collected. Each of two replicates was a 5 -min tow at $1 \mathrm{~m} \cdot \mathrm{s}^{-1}$, except when high zooplankton densities necessitated shorter tows. A flowmeter mounted at the mouth of the net provided estimates of volume sampled. Across a productivity gradient of Ohio reservoirs, Pomoxis spp. larvae are evenly distributed across the top $3 \mathrm{~m}$ of water in the day (Arend 2002). Thus, our sampling should provide an appropriate representation of larval densities in the epilimnion. Larvae were identified as gizzard shad, Lepomis spp., or Pomoxis spp. Similar numbers of myomeres prevented us from partitioning Pomoxis (Siefert 1969) or Lepomis genera into species.

To estimate density, at least 200 individuals were counted from a known percentage of the sample and then were extrapolated to a total estimate. If fewer than 200 individuals were in a sample, all individuals were counted. In some samples, however, larvae in a taxon were extremely rare (i.e., fewer than three larvae in at least $25 \%$ of the sample). To reduce processing time, we determined how well extrapolating from $25 \%$ predicted the complete count. For 36 estimates in 1998, we found the extrapolated estimate to be a strong predictor of the complete count $\left(r^{2}=0.69, F_{[1,34]}=77.3, P<0.0001\right)$. Hence, we used the extrapolated estimate when fewer than three larvae were counted in at least $25 \%$ of the sample for the samples processed in 1999-2000. We measured total length (nearest $0.01 \mathrm{~mm}$ ) of up to the first 50 Pomoxis spp. larvae encountered in all replicate samples (if less than 50 were collected, then all larvae were measured).

The 9-week sampling period was divided into three, 3-week periods: early, middle, and late. For all reservoir-years, we quantified age of Pomoxis spp. larvae during 1 week in the middle period (between late May and early June) because larvae were captured at the highest density and the widest length distribution at this time. For two reservoirs, we also estimated ages of larvae sampled during the early and late periods (for more details, see Larval survival section in Analyses). Thirty fish per site were selected for age estimation such that the length distribution of those to be aged mirrored the length distribution of previously measured fish. Right and left sagittal otoliths were removed and mounted on glass slides with Canada balsam. White crappie 
larvae lay their first ring at hatch, and subsequent rings are formed daily (Sweatman and Kohler 1991); we assumed that black crappie larvae also lay daily rings (sensu Pine and Allen 2001). Daily rings were counted at 100-200× magnification; number of rings estimated age in days. From a subset of 100 aged otoliths, readers disagreed no more than 2 days on $97 \%$ of the otoliths with age estimates less than 11 days. Disagreements on the remaining 3\% of otoliths were 3 days. Thus, all otoliths that had an initial age estimate less than 11 days were not aged by a second reader. Those initially aged to be at least 11 days were aged by a second reader. In this case, a mean of the two age estimates was used when the estimates differed by 3 or fewer days. When the age estimates differed by more than 3 days (occurred $\sim 10 \%$ of otoliths), a third "consensus" read occurred (Welker et al. 1994). In about 3\% of consensus reads, the otolith was determined to be unreadable.

\section{Collection and aging of juveniles}

Pomoxis spp. juveniles were sampled with a bottom trawl (mouth width $=3.7 \mathrm{~m}$; body length $=4.6 \mathrm{~m}$; bar mesh body $=8.4 \mathrm{~mm}$; bar mesh bag $=6.4 \mathrm{~mm}$; same as Pine and Allen 2001) during 11-14 July 2000. At each reservoir, we pulled four to seven trawls for a minimum of 3 min at depths of 3-6 $\mathrm{m}$ in both inflow and mid-reservoir sites. Trawls in deeper outflow sites, near the dam, yielded no juvenile crappies. Within each reservoir, Pomoxis spp. $(N=76-250$ per reservoir) were measured (nearest mm total length (TL)) and then pooled across sites. For aging of larvae, we used the length distribution to subsample a similarly distributed length distribution of 60 juveniles to be aged. Otoliths were prepared as described for larvae, except otoliths older than 20 days were ground with 1 - to 9 - $\mu \mathrm{m}$ wet-dry sandpaper owing to their more convex shape and opaque color.

\section{Analyses}

\section{Larval growth}

Daily growth rate (DGR) was estimated as (TL - 3.23)/ age, where TL (mm) represents total length at capture, 3.23 is TL at hatch, and age is the number of days since hatch. Length at hatch was the $y$ intercept in the age versus length regression for all larvae aged (TL $=3.23+$ 0.46 (age), $F_{[1,1720]}=10896, r^{2}=0.86, P<0.0001$ ) and was more than some previous estimates (2.2 mm TL, Auer 1982; $2.56 \mathrm{~mm}$ TL, Siefert 1969) and less than others (4 mm TL, Chatry and Conner 1980). From the inflow site only, we evaluated how growth was influenced by abiotic and biotic factors. Because larvae captured from the outflow site could have been transported from the inflow site, we related growth only with larvae captured at the inflow site. Larvae aged younger than 17 days were grouped as a function of reservoir, week of hatch, week of collection, and age-class (age-class I, 3-9 days; age-class II, 10-16 days) to estimate a mean daily growth rate of fishes that experienced similar conditions. Groups with at least five larvae were used. Within each age-class, we pooled growth rates of groups across reservoirs to evaluate whether variability in mean DGR was explained by some measure of zooplankton biomass (see below), density of all limnetic larvae (gizzard shad + Pomoxis spp. + Lepomis spp.), turbidity, and temperature. Because these four independent variables (with interactions) could generate multiple linear regression models, we used Akaike's information criterion (AIC) to choose the suite of models that best described our data set, rather than an iterative multiple regression that selects only the "best" model. From each of 12 a priori models that we hypothesized to explain variation in daily growth rate, we estimated parameters and residual sums of squares and then used Burnham and Anderson (1998) to calculate second-order AIC ( $\mathrm{AIC}_{\mathrm{c}}$; because our ratio of 
parameters to observations was $<40)$. For each model, $\Delta_{i}$ was reported as $\mathrm{AIC}_{c}-\min \left(\mathrm{AIC}_{c}\right)$, where $\min \left(\mathrm{AIC}_{\mathrm{c}}\right)$ is the smallest $\mathrm{AIC}_{\mathrm{c}}$ value among the models. Models for which $\Delta_{i} \leq 2$ provided "substantial" support in explaining variation in the data (Burnham and Anderson 1998).

For each group of larvae, the independent variables were the average value from the week of hatch until week of capture. All variables were measured weekly at each site, except temperature, which was measured by remote data loggers every $4 \mathrm{~h}$ at a $1-\mathrm{m}$ depth. We estimated turbidity (nearest 0.01 nephelometric turbidity units (NTU)) of euphotic water with a nepholometer in Acton, Burr Oak, and Caesar Creek; in the other reservoirs, we estimated turbidity with an inverse polynomial relationship between turbidity and secchi depth (NTU = $6.3+\left(3010.5 \cdot \operatorname{secchi}^{-1}\right)+\left(-236983.7 \cdot \operatorname{secchi}^{-2}\right)+\left(6572005.8 \cdot \operatorname{secchi}^{-3}\right), r^{2}=0.56, P<0.0001, N=$ 266). We hypothesized that two measures of zooplankton biomass could relate to growth: (1) total zooplankton biomass, which included all appropriately sized crustacean zooplankton and rotifers (first-feeding Pomoxis spp. larvae consume rotifers (Arend 2002; D.B. Bunnell, unpublished data), and (2) preferred crustacean zooplankton biomass, which included all appropriately sized calanoid and cyclopoid copepods, nauplii, and Diaphanosoma spp. (DeVries et al. 1998; Pope and Willis 1998; D.B. Bunnell, unpublished data). We used Pearson's correlation to determine which zooplankton measure to include in the general linear model, i.e., which was most positively correlated to growth. Because first-feeding Pomoxis spp. larvae are gape-limited (DeVries et al. 1998), our estimates included only the zooplankton biomass that Pomoxis spp. larvae were able to eat. Using mean TL of each group of larvae, we estimated Pomoxis spp. gape size, and the resultant maximum zooplankton size, with a TL - gape size regression (DeVries et al. 1998). We used the length measurements for each zooplankton taxon at each site per sampling week to estimate weekly biomass of appropriately sized zooplankton taxa as

$$
B=\sum p_{i}\left(A_{i}\right)\left(B_{i}\right)
$$

where $p_{i}$ is proportion of individuals in taxon $i$ that were smaller than or equal to the larval gape, $A_{i}$ is the total zooplankton abundance (number $\mathrm{L}^{-1}$ ) for taxon $i$, and $B_{i}$ is the mean calculated biomass of individuals in taxon $i$ that were smaller than or equal to the larval gape. For all rotifer taxa, $p_{i}=1.0$, except for Asplanchna spp., which can exceed the gape of Pomoxis spp. larvae smaller than $8 \mathrm{~mm}$ TL.

\section{Larval survival}

Collecting a sample of juvenile survivors enabled us to use otoliths to calculate hatch dates (day of capture - estimated age) and compare proportional weekly cohort distributions of juvenile survivors with proportional weekly cohort distributions of recently hatched larvae. For each juvenile aged, we calculated a hatch date and assigned it to a cohort. We then calculated a proportional cohort distribution of juvenile survivors for each reservoir.

To estimate a proportional cohort distribution of larvae, we sought to include only fish that had arrived in the limnetic zone since our previous sampling event. This approach eliminated biasing the distribution toward cohorts in which larvae were surviving well, as those cohorts could be sampled during multiple weeks. Larvae collected in the neuston net were aged as young as 4 days, corroborating when Pomoxis spp. larvae depart the nest and begin to feed exogenously (Siefert 1968). We assumed that all larvae recruited to the limnetic zone by age 5 days; in our weekly sampling schedule, the oldest fish that could have recruited to the limnetic 
zone between weekly sampling events would be age 11 days. Fish older than 11 days should have been captured in earlier sampling efforts and, thus, were not included in our later analyses. We are confident that our sample was representative of all larvae that initially recruited to the limnetic zone from the nest (i.e., that larvae did not starve before being sampled). Their size at hatch predicts that $50 \%$ of starved larvae will survive 14 days (Miller et al. 1988). With our weekly sampling schedule, starved Pomoxis spp. larvae would have to survive a maximum of 6 days before being collected, minimizing the likelihood that significant numbers of larvae died from starvation before being sampled.

To assign larvae to cohorts, we used reservoir-specific, length vs. age regressions, rather than reading otoliths of all larvae sampled. In each reservoir, the regression was developed using fish sampled during the middle period. In Caesar Creek and Burr Oak, insufficient sample sizes made regression estimation infeasible in early or late periods. However, early and late period regressions were developed for Pleasant Hill and LaDue to explore how potential differences in growth rates between periods could influence construction of the distribution. The regression assigned ages and weekly cohorts to all measured fish. At each site on each sampling day, we estimated the proportion represented by each cohort. We also used the ages to estimate the proportion of measured individuals that were 11 days or younger (i.e., recently hatched) and then multiplied that fraction by the total catch. Next, we multiplied the proportion of each cohort by this estimate of recently hatched larvae to generate a cohort-specific hatch density for each site sampling day combination. Because we could not link surviving juveniles to a specific site, we added cohort-specific densities across sites and sampling days and then determined a proportional cohort distribution of larvae for each reservoir.

In assigning cohorts to juveniles, we considered the likelihood that older juveniles were less likely to be sampled than younger juveniles, owing to higher cumulative mortality for the older ones (sensu Campana and Jones 1992). To correct for this, we used a daily juvenile mortality rate to standardize cohort distributions such that the juvenile abundance represented fish captured at similar ages. Specifically, we subtracted the median age of the youngest cohort sampled from the median age of each cohort. We then estimated the survival rate for the cohort during that period and multiplied the inverse of that survival rate by the relative abundance of each cohort (Methot 1983). Without knowing the daily mortality rate of juveniles, we expected it to be lower than that of larvae, which we estimated to be between 0.10 and 0.15 through catch curve analyses (D.B. Bunnell, unpublished data). We evaluated the effects of both a low and high juvenile mortality rate in correcting the juvenile hatch date distribution. We used 0.05 as a low daily mortality rate and 0.15 as a high one, the low rate being smaller than our larval mortality rate and the high rate being within the range measured for juvenile black crappies in Florida (0.09-0.25; Pine and Allen 2001).

With proportional cohort distributions for both larvae and juveniles, we first compared the distributions with a Kolmogorov-Smirnov $(\mathrm{K}-\mathrm{S})$ test. When the distributions differed, we calculated an index of cohort larval survival, $\beta_{i}$, as $J_{i} / H_{i}$, where $i$ represents cohorts 1 through 9 , $J_{i}$ is the proportion of juvenile crappies sampled from cohort $i$, and $H_{i}$ is the proportion of all larvae hatched from cohort $i$ (Crecco and Savoy 1985; Garvey et al. 2002). For all scenarios of daily juvenile mortality regimes (i.e., zero (uncorrected), low (0.05), and high (0.15)), we used Pearson's correlation to relate $\beta_{i}$ to variables measured during the week that larvae hatched and became exogenous feeders. Measured characteristics used in the analyses were the same as those used in the growth analyses: density of all fish larvae, temperature, turbidity, and two measures of appropriately sized zooplankton biomass (e.g., total zooplankton biomass or preferred 
crustacean biomass). We predicted survival to be negatively correlated with density of fish larvae and turbidity and positively correlated with zooplankton and temperature. If the predicted linkage was consistent for all three scenarios, then we concluded it to be insensitive to potential juvenile mortality regimes. If the predicted linkage occurred at fewer scenarios, then we concluded it to exist only under specific assumptions. Finally, if the predicted linkage was not realized under any scenario, then we concluded that it was not supported by our data.

For all measures of zooplankton biomass, we used $6.0 \mathrm{~mm}$ TL (i.e., predicted length at age 6 days) to determine the gape size (DeVries et al. 1998) and biomass (see eq. 1) of zooplankton sufficiently small for first-feeding larvae to consume each week. Because we could not determine whether juvenile survivors came from inflow or outflow sites and because zooplankton and temperature vary between sites, we used the proportion hatching from each site to weight the site-specific variables.

\section{Results}

\section{Zooplankton availability}

Density and composition (crustacean vs. rotifer) of zooplankton varied across weeks within reservoirs (Fig. 1). Crustacean biomass was generally always higher than rotifer biomass in all reservoirs except Acton Reservoir, the most eutrophic reservoir (see Table 1). Pleasant Hill also exhibited some weeks when rotifer biomass exceeded crustaceans, which was driven by high densities of Asplanchna spp. With regard to abundance, rotifers exceeded crustacean zooplankters at both sites of all reservoirs. In fact, across all reservoirs mean crustacean abundance was less than $50 \mathrm{~L}^{-1}$, with the highest abundance observed equaling $78 \mathrm{~L}^{-1}$ and the median density equaling $13 \mathrm{~L}^{-1}$. Mean total abundance (including rotifers) increased to at least $150 \mathrm{~L}^{-1}$ at all inflow sites and $60 \mathrm{~L}^{-1}$ at all outflow ones. Thus, fish larvae in each reservoir were faced with a prey environment that varied both in composition (i.e., rotifer and crustacean zooplankton) and in density (i.e., biomass and abundance) across weeks.

\section{Larval growth}

Mean growth rates of Pomoxis spp. larvae ranged from 0.43 to $0.57 \mathrm{~mm} \cdot \mathrm{day}^{-1}$. For firstfeeding larvae in age-class I (age 3-9 days), total zooplankton biomass was positively correlated with growth $(r=0.80, N=11$ groups, $P=0.003)$; preferred crustacean zooplankton biomass was unrelated to growth $(r=0.002, N=11$ groups, $P=0.95)$. Among a priori models, the one that included only total zooplankton bio-mass had the lowest $\mathrm{AIC}_{\mathrm{c}}$ value (Table 2), indicating the highest support for explaining variation in growth. As expected, growth increased with increasing total zooplankton biomass density $\left(95 \%\right.$ confidence limits of slope $=3.31^{-4}$ to $\left.1.19^{-3}\right)$. A second model that included total zooplankton biomass and density of fish larvae also deserved consideration for explaining variation with a $\Delta_{i}$ value less than 2.00 (Burnham and Anderson 1998). The slope of the larval fish density parameter, however, did not differ from zero ( $95 \%$ confidence limits $=-0.011$ to 0.001 ). Among older larvae in age-class II (ages 10-16 days), neither total zooplankton biomass $(r=0.20, N=8$ groups, $P=0.64)$ nor preferred crustacean zooplankton biomass $(r=0.28, N=8$ groups, $P=0.49$ ) was positively related to growth. Among a priori models, the four models that included only one slope parameter ranked the highest (Table 2). In each model, however, the slope did not differ from zero (95\% confidence limits: turbidity $=-0.01$ to 0.005 ; preferred crustacean zooplankton biomass $=-2.42^{-3}$ to $4.46^{-3}$; temperature $=-0.019$ to 0.021 ; larval fish density $=-0.008$ to 0.008 ), indicating that our 
measured variables were largely unsuccessful in explaining variation in growth of larvae older than 9 days.

\section{Larval survival in 2000}

To estimate cohort survival, $\beta$, we compared proportional cohort distributions of recently hatched larvae with those of surviving juveniles. For larvae, weekly cohorts were assigned using a length versus age regression derived from larvae sampled during the middle period in each reservoir. Length was a strong predictor of age in all reservoirs (range of $r^{2}=0.68$ to 0.84 , mean $=0.76$ ). To determine whether differences in growth rates between sampling periods would change the proportional cohort distribution, we compared a distribution that used period-specific (i.e., early, middle, and late) length vs. age regressions with one that applied the middle period regression to all periods in Pleasant Hill and LaDue reservoirs. For each, no differences existed (Kolmogorov - Smirnov test: LaDue, $\mathrm{K}-\mathrm{S}=0.007, D=0.01, P=1.00$; Pleasant Hill, $\mathrm{K}-\mathrm{S}=$ $0.004, D=0.008, P=1.00$ ), likely because the range of predicted age across periods was generally about 1 day (e.g., for an 8-mm fish, range of Pleasant Hill predicted ages = 7.9-9.1 days, range of LaDue predicted ages $=8.9-9.2$ days), which would rarely affect the assignment of a fish to a weekly cohort. Thus, applying the middle-period regression to all periods provided an accurate representation of proportional cohort distribution for larvae.

Fig. 1. Mean density of crustacean zooplankton (solid bars) and rotifer (open bars) biomass at the inflow and outflow sites of (a) Acton, $(b)$ Burr Oak, $(c)$ Caesar Creek, $(d)$ LaDue, and $(e)$ Pleasant Hill reservoirs as a function of week during May- June 2000.

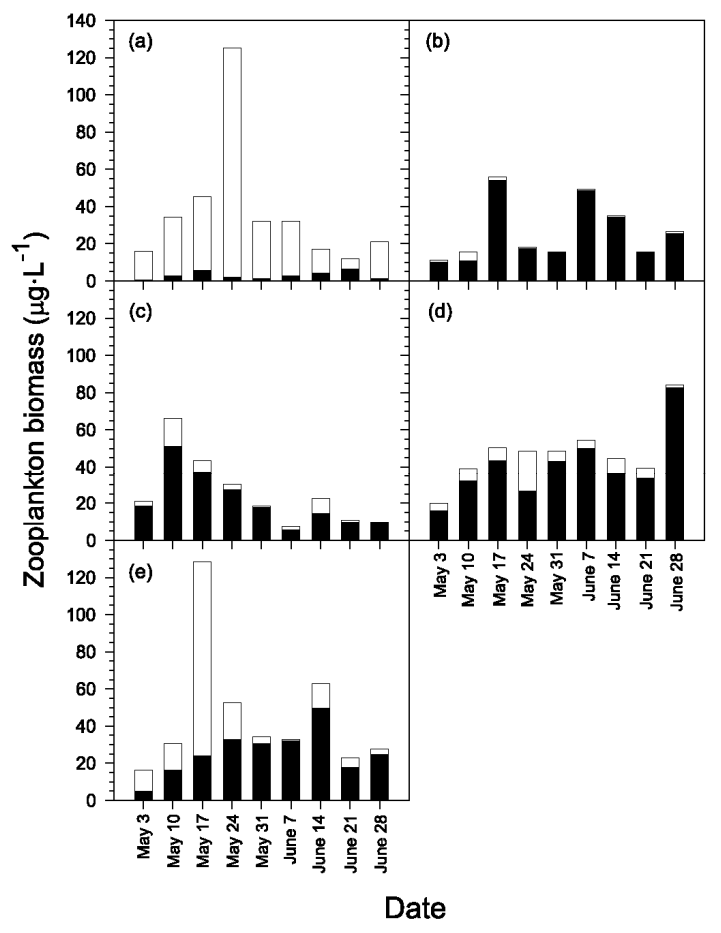

Within each reservoir, juvenile survivors ranged widely in size (minimum range $=29$ $\mathrm{mm}$; maximum range $=42 \mathrm{~mm}$ ) and age (minimum range $=28$ days; maximum range $=42$ 
days). Correcting for a higher cumulative juvenile mortality for earlier-hatched cohorts altered the juvenile cohort distributions: the higher the mortality rate, the higher the proportion of earlier cohorts (Fig. 2). Overall, the proportional hatch distribution of juveniles rarely matched that of larvae. Only when juvenile mortality was assumed to be high in Caesar Creek and Pleasant Hill (dotted lines in Figs. $2 c$ and $2 e$, respectively) were the distributions similar between juveniles and larvae (Kolmogorov-Smirnov test: Caesar Creek, $\mathrm{K}-\mathrm{S}=0.06, D=0.12, P=0.79$; Pleasant Hill, $\mathrm{K}-\mathrm{S}=0.06, D=0.12, P=0.81$ ). Comparing distributions in Acton was inappropriate because the proportion of early-hatching larvae was underestimated owing to larvae not being sampled in the second week of May.

Table 2. Rankings of a priori models to explain variation in larval growth of (a) age-class I and (b) age-class II Pomoxis spp. larvae from five Ohio reservoirs.

\begin{tabular}{lccccc}
\hline Model & $\mathrm{K}$ & \multicolumn{1}{c}{$\mathrm{AIC}_{\mathrm{c}}$} & \multicolumn{1}{l}{$\Delta_{i}$} & \multicolumn{1}{l}{$w_{i}$} & $r^{2}$ \\
\hline (a) Age-class I (3-9 days & old) & & & \\
ZP & 3 & -75.21 & 0.00 & 0.547 & 0.64 \\
ZP, L & 4 & -73.70 & 1.51 & 0.257 & 0.74 \\
ZP, Tp & 4 & -70.72 & 4.49 & 0.058 & 0.66 \\
ZP, Tu & 4 & -70.06 & 5.15 & 0.042 & 0.64 \\
ZP, ZP × Tp & 4 & -70.04 & 5.16 & 0.041 & 0.64 \\
ZP, ZP × Tu & 4 & -69.96 & 5.24 & 0.040 & 0.64 \\
ZP, L, Tu & 5 & -66.55 & 8.66 & 0.007 & 0.75 \\
L & 3 & -64.48 & 10.72 & 0.003 & 0.05 \\
Tp & 3 & -64.14 & 11.07 & 0.002 & 0.02 \\
Tu & 3 & -64.11 & 11.10 & 0.002 & 0.02 \\
ZP, Tp, Tu & 5 & -63.43 & 11.77 & 0.002 & 0.67 \\
ZP, Tp, Tu, L & 6 & -55.80 & 19.40 & 0.000 & 0.75 \\
(b) Age-class II $(\mathbf{1 0 - 1 6}$ days old) & & & \\
Tu & 3 & -44.89 & 0.00 & 0.323 & 0.12 \\
ZP & 3 & -44.54 & 0.35 & 0.272 & 0.08 \\
Tp & 3 & -43.89 & 1.00 & 0.196 & 0.00 \\
L & 3 & -43.85 & 1.03 & 0.193 & 0.00 \\
ZP, Tu & 4 & -36.26 & 8.63 & 0.004 & 0.20 \\
ZP, ZP $\times$ Tu & 4 & -35.74 & 9.15 & 0.003 & 0.14 \\
ZP, ZP $\times$ Tp & 4 & -35.55 & 9.34 & 0.003 & 0.12 \\
ZP, L & 4 & -35.47 & 9.42 & 0.003 & 0.11 \\
ZP, Tp & 4 & -35.28 & 9.60 & 0.003 & 0.09 \\
ZP, Tp, Tu & 5 & -17.68 & 27.20 & 0.000 & 0.20 \\
ZP, Tu, L & 5 & -17.67 & 27.22 & 0.000 & 0.20 \\
ZP, Tp, Tu, L & 6 & 37.67 & 82.55 & 0.000 & 0.27 \\
\hline
\end{tabular}

Note: Rank was determined by $\mathrm{AIC}_{\mathrm{c}}$ values (smallest value equals highest rank). In each model, $\mathrm{ZP}$ represents zooplankton biomass, L represents density of all fish larvae, Tp represents water temperature, and Tu represents turbidity. Column headings include $K$ (the number of slope parameters plus the error and intercept), $\Delta_{i}$ (difference between each model and the model with the minimum $\mathrm{AIC}_{\mathrm{c}}$ value), $w_{\mathrm{i}}$ (the relative "weight" of evidence for each model), and $r^{2}$ (the proportion of variance explained by the model).

When the cohort distributions of larvae and juveniles differed, we used Pearson's correlation to evaluate whether the differential cohort survival was related to abiotic and biotic characteristics during the week when larvae hatched and became exogenous feeders. Because of our uncertainty regarding juvenile mortality, we ran these analyses under zero ( 0.0 daily mortality), low (0.05), and high (0.15) daily juvenile mortality rate scenarios. Within each reservoir, correlations between cohort survival and biotic and abiotic characteristics during hatch week revealed few correlations (Table 3). Survival increased with total zooplankton biomass 
only in Burr Oak, when juvenile mortality was assumed to be zero or low (0.05). Preferred crustacean zooplankton biomass also failed to yield correlations with survival. In addition, neither density of fish larvae nor turbidity was ever negatively associated with survival, which was counter to our predictions. Temperature, which could have increased survival by increasing egg development or larval growth rate, was never positively associated with survival. Thus, among a range of possible juvenile mortality scenarios, we failed to document support that the abiotic and biotic environment in the first week of life was critical to survival to the juvenile stage.

Fig. 2. Survival of Pomoxis spp. larvae to the juvenile stage in (a) Acton, (b) Burr Oak, (c) Caesar Creek, (d) LaDue, and (e) Pleasant Hill reservoirs as a function of hatch week for each cohort. Proportion of cohorts of larvae (sampled May-June) is depicted as shaded, vertical bars on the left $y$-axis, and the proportion of cohorts of juveniles (sampled 11-14 July 2000) is depicted as lines on the right $y$-axis. Cohort distributions of juveniles were corrected for differences in cumulative mortality between the oldest and youngest cohorts (see Materials and methods). For clarity, the two extreme mortality possibilities are depicted: zero mortality (i.e., no correction) with the solid line and high mortality (daily mortality $=0.15$ ) with the dotted line. The asterisk $\left(^{*}\right)$ on the proportional distribution of larvae in (a) indicates that the distribution likely underestimates the proportion of larvae hatched during the week of 3 May 2000 as a result of no larval samples collected during the week of 10 May 2000 in Acton.

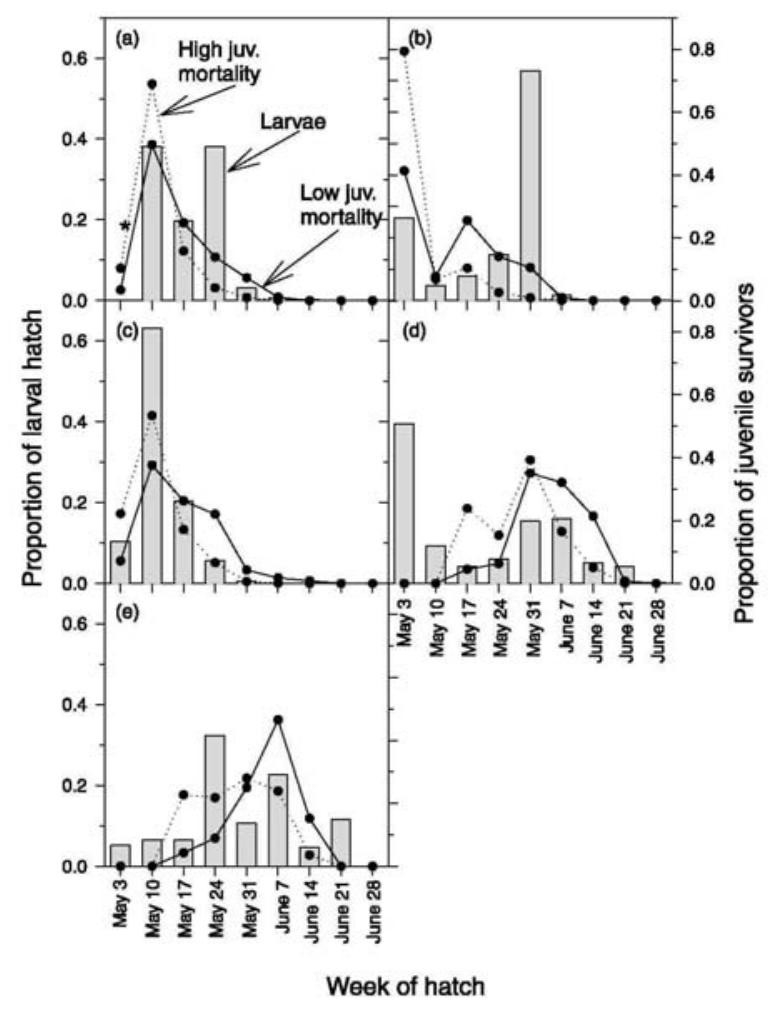


Table 3. Pearson's correlation coefficient and $P$ value (in parentheses) between $\beta_{\mathrm{i}}$, an index of Pomoxis spp. Larval survival during 2000, and total zooplankton biomass (crustatceans and rotifers), density of all fish larvae (i.e., gizzard shad, Lepomis spp., Pomoxis spp.), turbity, and temperature during the week of Pomoxis spp. Hatch in four Ohio reservoirs under three different juvenile mortality regimes: zero ( 0.0 daily morality), low ( 0.5 daily mortality), and high (0.15 daily mortality).

\begin{tabular}{|c|c|c|c|c|c|c|c|c|c|c|c|c|c|}
\hline \multirow[b]{3}{*}{ Reservoir } & \multirow[b]{3}{*}{$N$} & \multicolumn{3}{|c|}{ Zooplankton } & \multirow{2}{*}{\multicolumn{3}{|c|}{$\begin{array}{l}\text { Density of all fish larvae } \\
\text { Juvenile mortality correction }\end{array}$}} & \multirow{2}{*}{\multicolumn{3}{|c|}{ 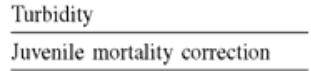 }} & \multirow{2}{*}{\multicolumn{3}{|c|}{$\begin{array}{l}\text { Temperature } \\
\text { Juvenile mortality correction }\end{array}$}} \\
\hline & & \multicolumn{3}{|c|}{ Juvenile mortality correction } & & & & & & & & & \\
\hline & & Zero & Low & High & Zero & Low & High & Zero & Low & High & Zero & Low & High \\
\hline Burr Oak & 7 & $\begin{array}{c}0.87 \\
(0.01)\end{array}$ & $\begin{array}{c}0.86 \\
(0.01)\end{array}$ & $\begin{array}{c}0.34 \\
(0.45)\end{array}$ & $\begin{array}{c}0.85 \\
(0.02)\end{array}$ & $\begin{array}{c}0.47 \\
(0.29)\end{array}$ & $\begin{array}{c}-0.34 \\
(0.46)\end{array}$ & $\begin{array}{c}0.05 \\
(0.92)\end{array}$ & $\begin{array}{c}-0.10 \\
(0.83)\end{array}$ & $\begin{array}{c}-0.26 \\
(0.57)\end{array}$ & $\begin{array}{c}-0.36 \\
(0.43)\end{array}$ & $\begin{array}{c}-0.57 \\
(0.18)\end{array}$ & $\begin{array}{c}-0.76 \\
(0.05)\end{array}$ \\
\hline Caesar Creek & 7 & $\begin{array}{c}-0.39 \\
(0.39)\end{array}$ & $\begin{array}{c}-0.53 \\
(0.23)\end{array}$ & & $\begin{array}{c}0.59 \\
(0.16)\end{array}$ & $\begin{array}{c}0.66 \\
(0.11)\end{array}$ & & $\begin{array}{c}0.06 \\
(0.90)\end{array}$ & $\begin{array}{c}-0.12 \\
(0.79)\end{array}$ & & $\begin{array}{c}0.77 \\
(0.04)\end{array}$ & $\begin{array}{c}0.66 \\
(0.11)\end{array}$ & \\
\hline LaDue & 9 & $\begin{array}{l}-0.02 \\
(0.97)\end{array}$ & $\begin{array}{c}0.12 \\
(0.77)\end{array}$ & $\begin{array}{l}0.42 \\
(0.26)\end{array}$ & $\begin{array}{c}0.24 \\
(0.53)\end{array}$ & $\begin{array}{c}0.13 \\
(0.75)\end{array}$ & $\begin{array}{c}-0.23 \\
(0.55)\end{array}$ & $\begin{array}{l}-0.13 \\
(0.74)\end{array}$ & $\begin{array}{c}0.02 \\
(0.95)\end{array}$ & $\begin{array}{c}0.82 \\
(0.01)\end{array}$ & $\begin{array}{c}0.38 \\
(0.31)\end{array}$ & $\begin{array}{c}0.23 \\
(0.56)\end{array}$ & $\begin{array}{l}-0.42 \\
(0.26)\end{array}$ \\
\hline Pleasant Hill & 8 & $\begin{array}{c}-0.18 \\
(0.68)\end{array}$ & $\begin{array}{c}-0.19 \\
(0.65)\end{array}$ & & $\begin{array}{c}0.33 \\
(0.43)\end{array}$ & $\begin{array}{c}0.50 \\
(0.21)\end{array}$ & & $\begin{array}{c}0.73 \\
(0.04)\end{array}$ & $\begin{array}{c}0.61 \\
(0.11)\end{array}$ & & $\begin{array}{c}0.56 \\
(0.15)\end{array}$ & $\begin{array}{c}0.44 \\
(0.27)\end{array}$ & \\
\hline
\end{tabular}

Note: Significant $(P \leq 0.05)$ correlations are depicted in bold $N$ is the number of weekly cohorts for which $\beta_{\mathrm{i}}$ was measured in each reservoir. We did not estimate correlations in Acton Lake because no larval samples were collected in the second week of May, which underestimated the number of early-hatching larvae. We did not estimate correlations for the high juvenile mortality scenario for Cesar Creek and Pleasant Hill because those proportional distributions were similar between juveniles and larvae.

\section{Discussion}

We hypothesized that growth and survival of Pomoxis spp. larvae would increase with zooplankton biomass and temperature and decline with turbidity and density of larval fish competitors. As predicted, growth of first-feeding larvae (age 3-9 days) increased with biomass of crustacean zooplankton and rotifers; other variables, however, were unimportant. Growth of older larvae (age 10-16 days) was unrelated to all measured variables. With regard to survival, higher zooplankton biomass for first-feeding larvae was associated with high survival in only one of four reservoirs. None of the remaining variables revealed the hypothesized associations. Thus, despite positive effects of zooplankton biomass on growth of first-feeding Pomoxis spp. larvae, we found minimal evidence that survival to the juvenile stage was enhanced by higher zooplankton biomass.

For first-feeding Pomoxis spp. larvae (age-class I), total zooplankton biomass best explained daily growth rate, suggesting rotifers and other small nonpreferred prey (e.g., genera Bosmina, Chydorus, Eubosmina, Asplanchna, Brachionus, etc.) improved growth of gapelimited larvae. Such a strong relationship $\left(r^{2}=0.64\right)$, however, was not documented for older, age-class II larvae. Conceivably, characterizing the growth environment is more difficult for older larvae than for younger larvae. Relative to older larvae, younger larvae may well be more closely associated with their sampling location and hence their abiotic and biotic environment. Previous work with Pomoxis spp. larvae provides somewhat different results. In Illinois reservoirs, growth was negatively correlated with crustacean zooplankton density and temperature but positively correlated with copepod nauplii density and percent of water volume occupied by littoral habitat (Claramunt and Wahl 2000). We did not evaluate volume of littoral habitat and we documented that temperature, as well as fish larvae and turbidity, were unrelated to growth. We are unsure why warmer temperatures did not increase growth. Growth rates in Ohio reservoirs (range $=0.43-0.57 \mathrm{~mm} \cdot \mathrm{day}^{-1}$, mean $=0.50 \mathrm{~mm} \cdot \mathrm{day}^{-1}$ ) were within the range of those measured in Illinois (range $=0.26-1.00 \mathrm{~mm} \cdot$ day $^{-1}$, mean $=0.58 \mathrm{~mm} \cdot \mathrm{day}^{-1}$; Claramunt and Wahl 2000) but higher than those measured in Alabama (range $=0.25-0.35 \mathrm{~mm} \cdot \mathrm{day}^{-1}$; Dubuc 
and DeVries 2002).

To evaluate factors influencing survival of Pomoxis spp. larvae, we first compared proportional cohort distributions of larvae and juveniles constructed from otoliths. Proportional distributions of larvae and juveniles differed in all reservoirs when corrections for juvenile mortality were not made. Proportional cohort distributions of juveniles, however, should be adjusted to account for the probability that older cohorts are less likely to be captured than younger cohorts owing to a higher cumulative mortality rate (sensu Campana and Jones 1992). Ideally, the juvenile distribution would be adjusted by a known juvenile mortality rate; in our case, however, only larval mortality estimates were available $(0.10-0.15$; D.B. Bunnell, unpublished data). Without this estimate, we adjusted the distribution to reflect both a relatively low (0.05) and high (0.15) daily mortality rate to cover a range of scenarios. Although black crappie juvenile mortality was estimated as high as 0.25 in Florida (Pine and Allen 2001), we used 0.15 because we would not expect mortality to increase between the larval and juvenile periods (Campana and Jones 1992). Comparison of these adjusted juvenile distributions to larval cohort distributions maintained differences in the low mortality scenario for each reservoir. In the high mortality scenario, however, the distributions of larval and juvenile cohorts were similar in two of four reservoirs. Thus, unless mortality of juveniles was high, the proportion of larvae hatched was not a good indicator of the number of juveniles that survived. We hypothesized that zooplankton biomass, temperature, turbidity, and number of larval competitors present during hatch week could explain this variable cohort survival.

Given their extremely small size at hatch among freshwater species and the potential negative impact of larval competitors, we expected survival of Pomoxis spp. larvae to be most influenced by low zooplankton biomass. Indeed, many experiments predict that survival of freshwater larvae should increase with zooplankton densities (Hart and Werner 1987; Welker et al. 1994), and reviews reveal that resistance to starvation increases with length at hatch (e.g., Miller et al. 1988). With regard to size at hatch, Pomoxis spp. are among the smallest 3\% of freshwater larvae in the Great Lakes basin (Auer 1982). Previous research in hypereutrophic Ohio reservoirs also predicts that survival of Pomoxis spp. larvae may be compromised by high densities of gizzard shad larvae, which can deplete zooplankton densities for larvae that co-occur or hatch later (see review by Stein et al. 1995).

Despite the suggestions that zooplankton densities for first-feeding larvae should be important, supporting evidence for this hypothesis was limited at best. Without adjusting for juvenile mortality, survival increased with total zooplankton biomass only in Burr Oak. Adjusting for juvenile mortality did not reveal positive associations in the other three reservoirs, and the relationship in Burr Oak was not present if juvenile mortality was high. Thus, in our multireservoir approach, zooplankton biomass and survival were generally unrelated, even when corrections for juvenile mortality were made. It is worth exploring, however, why this relationship occurred in Burr Oak, which was the least productive reservoir in terms of chlorophyll $a$ but had densities of crustacean zooplankton biomass that were similar to other systems. One unique factor was its consistently low biomass of rotifers. Given the importance of including rotifer biomass in generating a strong predictive relationship between growth of firstfeeding larvae and zooplankton, rotifers also may enhance survival of first-feeding larvae.

Why were negative effects of gizzard shad on Pomoxis spp. survival not detected? One explanation could be that our study reservoirs included mostly mesotrophic reservoirs, whereas negative gizzard shad effects are strongest in hypereutrophic ones (sensu Stein et al. 1995). Unfortunately, we could not relate our index of survival to densities of zooplankton biomass or 
fish larvae in Acton, the most eutrophic reservoir with the highest densities of gizzard shad larvae (15 $\mathrm{m}^{-3}$ on 18 May 2000) because of failed larval sampling during 1 week in early May. If cohort survival had been calculated for Acton, might negative impacts of gizzard, through consumption of zooplankton, have been revealed? Although we cannot know, it is notable that $80 \%$ of juvenile survivors were hatched 10 May to 24 May 2000, when densities of zooplankton were dominated by rotifers (rotifers, 34-315 L L $\mathrm{L}^{-1}, 31.2-122.9 \mu \mathrm{g} \cdot \mathrm{L}^{-1}$; crustaceans, $2-6 \mathrm{~L}^{-1}, 2.2-$ $6.1 \mu \mathrm{g} \cdot \mathrm{L}^{-1}$ ). We would have expected such a low density of crustaceans to result in poor survival. However, because such a high proportion of the juvenile survivors were hatched during those weeks, rotifers again appear more important to sustaining growth and survival of first-feeding larvae than previously thought, especially in highly productive reservoirs.

Our freshwater field study joins others that have failed to relate higher zooplankton densities to increased survival (e.g., Welker et al. 1994; Betsill and Van Den Avyle 1997; Garvey et al. 2002). How can these field results be reconciled with laboratory studies that reveal survival to increase with zooplankton densities? In our view, whereas the laboratory evidence does indeed demonstrate the positive effects of zooplankton, it also demonstrates the hardiness of first-feeding larvae. Although no starvation experiments have been conducted on crappie larvae, time to $50 \%$ survival was about 7 days after first-feeding had begun for pumpkinseed larvae (Lepomis gibbosus) (Hart and Warner 1987), which is in the same family and just slightly longer at hatch than Pomoxis spp. (Auer 1982). Length at hatch versus time to $50 \%$ mortality regression generated in the review paper by Miller et al. (1988) predicts that $50 \%$ of starved crappie larvae could survive 14 days. Of course, in nature, spatial patchiness of zooplankton or low visibility could lead to a short-term, zero-prey environment, i.e., approximating the laboratory starvation experiments. In our view, however, starvation for several consecutive days is unlikely. Thus, starvation alone is unlikely to regulate survival of crappies or other freshwater larvae.

Our failure to link survival of Pomoxis spp. larvae to gizzard shad, via low zooplankton biomass, supports previous experimental work (Pope and DeVries 1994). Complementary research in these same Ohio reservoirs reveals that densities of adults and subsequent larvae limit recruitment to age-2 (D.B. Bunnell, unpublished data). If crappie year-class strength is indeed set by larval density (Sammons and Bettoli 1998; D.B. Bunnell, unpublished data), then processes governing mortality between the larval period and age- 2 should be fairly similar across Ohio reservoirs. Because factors that vary across reservoirs (e.g., zooplankton, turbidity, density of fish larvae) did not influence larval survival, our results are consistent with the hypothesis that year-class strength is set by density of hatched larvae.

If survival of Pomoxis spp. larvae is unrelated to zooplankton biomass, temperature, turbidity, and larval fish density, what other mechanisms could regulate larval survival? In terms of abiotic factors, the impact of wave action resulting from strong winds during late spring and early summer storms may reduce survival of limnetic larvae. However, we know of no supporting evidence for this hypothesis. Predation remains a viable hypothesis (e.g., Mason and Brandt 1996). Potential predators of larvae are numerous, including earlier-hatched larvae, such as cannibalistic Pomoxis spp. larvae, or limnetic walleye and yellow perch, as well as other limnetic adults such as white crappie (Kim and DeVries 2001). In our view, multiple biotic and abiotic factors likely interact to regulate survival of larvae.

In conclusion, increasing densities of zooplankton biomass increased growth rates of first-feeding Pomoxis spp. larvae, as expected. With this result, we expected to document higher larval survival when zooplankton biomass was high. However, survival increased with zooplankton biomass only in one of four reservoirs. Temperature, turbidity, and density of fish 
larvae occurring during the first week of life also were unrelated to survival to the juvenile stage, suggesting that the initiation of exogenous feeding is not critical for Pomoxis spp. survival. Given their small size at hatch (among the smallest 3\% of freshwater larvae), we expected crappies to be quite vulnerable to starvation at first-feeding. Conversely, Pomoxis spp. larvae survived despite low crustacean zooplankton abundance $\left(<50 \mathrm{~L}^{-1}\right)$ across mesotrophic and eutrophic reservoirs. In our view, these results cast doubt on whether zooplankton contributes to survival of freshwater larvae. This work joins previous studies in failing to link larval survival to zooplankton biomass (e.g., Garvey et al. 2002), despite countering experimental evidence that low zooplankton should both directly (through starvation; Hart and Werner 1987; Welker et al. 1994) and indirectly (through slow growth and small body size; Rice et al. 1987; Miller et al. 1988) compromise larval survival.

\section{Acknowledgments}

We thank B. Pine for teaching us how to effectively sample juvenile crappies. J. Fricke, J. Pyzoha, S. Thomas, J. Sieber-Denlinger, D. Glover, R. Ginsberg, D. Gloeckner, M. Haugen, C. Hutt, B. Lutmerding, H. McLean, S. Miehls, A. Peer, J. Ritchie, M. Schmidt, A. Spencer, M. Thomas, M. Tomasi, J. Williams, and S. Hale and the Ohio Department of Natural Resources, Division of Wildlife, provided valuable assistance with fieldwork and laboratory processing. M. Vanni was most helpful in estimating chlorophyll a. M. Allen, J. Holomuzki, E. Marschall, D. Secor, and an anonymous reviewer provided helpful and insightful suggestions. This research was funded by Federal Aid in Sport Fish Restoration Project F-69-P, administered jointly by U.S. Fish and Wildlife Service and Ohio Department of Natural Resources, Division of Wildlife, National Science Foundation grant DEB 9726877 to RAS and MJG, and the Department of Evolution, Ecology, and Organismal Biology at The Ohio State University.

\section{References}

Arend, K.K. 2002. Do vertical gradients affect larval fish depth distribution and prey electivity among reservoirs that vary in productivity? M.Sc. thesis, Ohio State University, Columbus, Ohio.

Auer, N.A. 1982. Identification of larval fishes of the Great Lakes basin with emphasis on the Lake Michigan drainage. Great Lakes Fishery Commission, Ann Arbor, Mich.

Betsill, R.K., and Van Den Avyle, M.J. 1997. Effect of temperature and zooplankton abundance on growth and survival of larval threadfin shad. Trans. Am. Fish. Soc. 126: 999-1011.

Burnham, K.P., and Anderson, D.A. 1998. Model selection and inference. Springer-Verlag, New York.

Campana, S.E., and Jones, C.M. 1992. Analysis of otolith microstructure data. In Otolith microstructure examination and analysis. Edited by D.K. Stevenson and S.E. Campana. Can. Spec. Publ. Fish. Aquat. Sci. No. 117. pp. 73-100.

Chatry, M.F., and Conner, J.V. 1980. Comparative developmental morphology of the crappies, Pomoxis annularis and P. nigromaculatus. Biol. Serv. Program U.S. Fish Wildl. Serv. 43: 45-57.

Claramunt, R.M., and Wahl, D.H. 2000. The effects of abiotic and biotic factors in determining larval fish growth rates: a comparison across species and reservoirs. Trans. Am. Fish. Soc. 129: 835-851.

Crecco, V.A., and Savoy, T.F. 1985. Effects of biotic and abiotic factors on growth and relative survival of young American shad, Alosa sapidissima, in the Connecticut River. Can. J. Fish. Aquat. Sci. 42: 1640-1648.

Crowder, L.B., McDonald, M.E., and Rice, J.A. 1987. Understanding recruitment of Lake Michigan fishes: the importance of size-based interactions between fish and zooplankton. Can. J. Fish. Aquat. Sci. 44(Suppl. 2): 141-147.

Culver, D.A., Boucherle, M.M., Bean, D.J., and Fletcher, J.W. 1985. Biomass of freshwater crustacean zooplankton from length-weight regressions. Can. J. Fish. Aquat. Sci. 42: 1380-1390.

DeVries, D.R., and Stein, R.A. 1992. Complex interactions between fish and zooplankton: quantifying the role of an open-water planktivore. Can. J. Fish. Aquat. Sci. 49: 1216-1227.

DeVries, D.R., Bremigan, M.T., and Stein, R.A. 1998. Prey selection by larval fishes as influenced by available zooplankton and gape limitation. Trans. Am. Fish. Soc. 127: 1040-1050.

Doohan, M. 1973. An energy budget for adult Brachionus plicatilis Muller (Rotatoria). Oecologia, 13: 351-362.

Dubuc, R.A., and DeVries, D.R. 2002. An exploration of factors influencing crappie early life history in three Alabama impoundments. Trans. Am. Fish. Soc. 131: 476-491.

Dumont, H.J., Van de Velde, I., and Dumont, S. 1975. The dry weight estimate of biomass in a selection of 
Cladocera, Copepoda, and Rotifera from the plankton, periphyton and benthos of continental waters. Oecologia, 19: 75-97.

Garvey, J.E., and Stein, R.A. 1998. Competition between larval fishes in reservoirs: the role of relative timing of appearance. Trans. Am. Fish. Soc. 127: 1021-1039.

Garvey, J.E., Dingledine, N.A., Donovan, N.S., and Stein, R.A. 1998. Exploring spatial and temporal variation within reservoir food webs: predictions for fish assemblages. Ecol. Appl. 8: 104- 120.

Garvey, J.E., Herra, T.P., and Leggett, W.C. 2002. Protracted reproduction in sunfish: the temporal dimension in fish recruitment revisited. Ecol. Appl. 12: 194-205.

Hart, T.F., and Werner, R.G. 1987. Effects of prey density on growth and survival of white sucker, Catostomus commersoni, and pumpkinseed, Lepomis gibbosus, larvae. Environ. Biol. Fishes, 18: 41-50.

Hjort, J. 1914. Fluctuations in the great fisheries of northern Europe. Rapp. P-v. Réun. Cons. Perm. Int. Explor. Mer, 20: $1-228$.

Houde, E.D. 1987. Fish early life dynamics and recruitment variability. Am. Fish. Soc. Symp. 2: 17-29.

Houde, E.D. 1994. Differences between marine and freshwater fish larvae: implications for recruitment. ICES J. Mar. Sci. 51: 91-97.

Houde, E.D. 1997. Patterns and consequences of selective processes in teleost early life histories. In Early life history and recruitment in fish populations. Edited by R.C. Chambers and E.A. Trippel. Chapman and Hall, London. pp. 173-196.

Hunter, J.R. 1981. Feeding ecology and predation of marine fish larvae. In Marine fish larvae: morphology, ecology and relation to fisheries. Edited by R. Lasker. University of Washington Press, Seattle. pp. 33-79.

Kim, G.W., and DeVries, D.R. 2001. Adult fish predation on freshwater limnetic fish larvae: a mesocosm experiment. Trans. Am. Fish. Soc. 130: 189-203.

Mason, D.M., and Brandt, S.B. 1996. Effect of alewife predation on survival of larval yellow perch in an embayment of Lake Ontario. Can. J. Fish. Aquat. Sci. 53: 1609-1617.

Methot, R.D. 1983. Seasonal variation in survival of larval northern anchovy, Engraulis mordax, estimated from the age distribution of juveniles. Fish. Bull. 81: 741-750.

Miller, T.J., Crowder, L.B., Rice, J.A., and Marschall, E.A. 1988. Larval size and recruitment mechanisms in fishes: toward a conceptual framework. Can. J. Fish. Aquat. Sci. 45: 1657-1670.

Miner, J.G., and Stein, R.A. 1993. Interactive influence of turbidity and light on larval bluegill (Lepomis macrochirus) foraging. Can. J. Fish. Aquat. Sci. 50: 781-788.

Pine, W.E., and Allen, M.S. 2001. Differential growth and survival of weekly age-0 black crappie cohorts in a Florida lake. Trans. Am. Fish. Soc. 130: 80-91.

Pope, K.L., and DeVries, D.R. 1994. Interactions between larval white crappie and gizzard shad: quantifying mechanisms in small ponds. Trans. Am. Fish. Soc. 123: 975-987.

Pope, K.L., and Willis, D.W. 1998. Early life history and recruitment of black crappie (Pomoxis nigromaculatus) in two South Dakota waters. Ecol. Freshw. Fish, 7: 56-68.

Rice, J.A., Crowder, L.B., and Binkowski, F.P. 1987. Evaluating potential sources of mortality for larval bloater (Coregonus hoyi): starvation and vulnerability to predation. Can. J. Fish. Aquat. Sci. 44: 467-472.

Rosen, R.A. 1981. Length - dry weight relationships of some freshwater zooplankton. J. Freshw. Ecol. 1: 225-229.

Ruttner-Kolinsko, A. 1977. Suggestions for biomass calculations of plankton rotifers. Commun. Int. Assoc. Theor. Appl. Limnol. 8: 71-76.

Sammons, S.M., and Bettoli, P.W. 1998. Larval sampling as a fisheries management tool: early detection of yearclass strength. N. Am. J. Fish. Manag. 18: 137-143.

Siefert, R.E. 1968. Reproductive behavior, incubation, and mortality of eggs, and post-larval food selection in the white crappie. Trans. Am. Fish. Soc. 97: 252-259.

Siefert, R.E. 1969. Characteristics for separation of white and black crappie larvae. Trans. Am. Fish. Soc. 98: 326328.

Smith, S.M., Maceina, M.J., and Dunham, R.A. 1994. Natural hybridization between black crappie and white crappie in Weiss Lake, Alabama. Trans. Am. Fish. Soc. 123: 71-79.

Stahl, T.P., and Stein, R.A. 1994. Influence of larval gizzard shad (Dorosoma cepedianum) density on piscivory and growth of young-of-year saugeye (Stizostedion vitreum $\times$ S. canadense). Can. J. Fish. Aquat. Sci. 51: 19932002.

Stein, R.A., DeVries, D.R., and Dettmers, J.M. 1995. Food-web regulation by a planktivore: exploring the generality of the trophic cascade hypothesis. Can. J. Fish. Aquat. Sci. 52: 2518-2526.

Sweatman, J.J., and Kohler, C.C. 1991. Validation of daily otoliths increments for young-of-the-year white crappies. N. Am. J. Fish. Manag. 11: 499-503. 
Welker, M.T., Pierce, C.L., and Wahl, D.H. 1994. Growth and survival of larval fishes: roles of competition and zooplankton abundance. Trans. Am. Fish. Soc. 123: 703-717.

Wetzel, R.G. 2001. Limnology: lake and river ecosystems. Academic Press, San Diego, Calif. 